\title{
Erratum to: More frequent showers and thunderstorm days under a warming climate: evidence observed over Northern Eurasia from 1966 to 2000
}

\author{
Hengchun Ye ${ }^{1}$ $~$ Eric J. Fetzer $^{2} \cdot$ Sun Wong $^{2} \cdot$ Bjorn H. Lambrigtsen $^{2} \cdot$ Tao Wang $^{2}$ • \\ Luke Chen ${ }^{2}$ Van Dang ${ }^{2}$
}

Published online: 7 February 2017

(C) Springer-Verlag Berlin Heidelberg 2017

\section{Erratum to: Clim Dyn \\ DOI 10.1007/s00382-016-3412-0}

In the original publication of the article, the fourth coauthor name has been published incorrectly. The correct name should be "Tao Wang".

The original article has been updated accordingly.

The online version of the original article can be found under doi:10.1007/s00382-016-3412-0.

Hengchun Ye

hye2@calstatela.edu

1 Department of Geosciences and Environment, California

State University, Los Angeles, Los Angeles, CA 90032-8222,

USA

2 JPL, California Institute of Technology, Pasadena, CA, USA 